\section{HOMOCITRATE SYNTHASE AS \\ THE CRUCIAL SITE OF \\ THE LYSINE EFFECT ON PENICILLIN BIOSYNTHESIS}

\section{G. Friedrich* and A. L. Demain \\ Department of Nutrition and Food Science Massachusetts Institute of Technology Cambridge, Massachusetts 02139, U.S.A. (Received for publication June 28, 1977)}

Lysine inhibition of penicillin biosynthesis has been known for many years. ${ }^{1)}$ The addition of $\alpha$-aminoadipate not only reverses this inhibition, but also stimulates penicillin formation in the absence of exogenous lysine. ${ }^{2}$ Because both lysine and penicillin biosynthesis involve $\mathrm{L}-\alpha$ aminoadipate as an intermediate, MASUREKAR and DeMAIN ${ }^{3)}$ suggested that lysine inhibition of penicillin biosynthesis was due to inhibition by lysine of an early enzyme in its biosynthetic path. They later demonstrated that lysine inhibited the initial enzyme, homocitrate synthase, in vivo. $\left.{ }^{4}\right)$ Although the above studies showed that homocitrate synthase in mycelia of Penicillium chrysogenum is inhibited by lysine, this fact alone does not prove that this reaction is the only one inhibitable by lysine or even that lysine inhibition of this enzyme is responsible for inhibition of penicillin formation. The present work was done to examine this point.

P. chrysogenum Wis. 54-1255 (ATCC 28089) was maintained as a conidial suspension. About $10^{6}$ spores were inoculated into $40 \mathrm{ml}$ SABOURAUDdextrose broth supplemented with $0.1 \%$ yeast extract in $250 \mathrm{ml}$ triple-baffled Erlenmeyer flasks. The flasks were shaken at $250 \mathrm{rev}$./minute in a Psychrotherm incubator (New Brunswick Scientific Co.) for 40 hours at $25^{\circ} \mathrm{C}$. The mycelia were harvested by sterile filtration and washed three times with $80 \mathrm{ml}$ sterile distilled water. The washed cake was resuspended in $40 \mathrm{ml}$ sterile water, and $5 \mathrm{ml}$ were inoculated into $35 \mathrm{ml}$ defined penicillin production medium ${ }^{4}$ in 250 $\mathrm{ml}$ flasks. Mycelia from three production flasks were harvested by filtration after 48 hours. At this time, the specific productivity of penicillin was at its highest level (unpublished data). The mycelia were washed three times with $80 \mathrm{ml}$

* Present address: Gesellschaft für Strahlen-und Umweltforschung mbH, Institut für Mikrobiologie, 3400 Göttingen, West Germany. sterile distilled water and were resuspended in an unbaffled 500-ml Erlenmeyer flask containing $120 \mathrm{ml}$ of starvation medium $[12 \mathrm{ml}$ mineral salts mixture, $\left.{ }^{4}\right) 1.2 \mathrm{~g}\left(\mathrm{NH}_{4}\right)_{2} \mathrm{HPO}_{4}$, and $3.3 \mathrm{mg}$ cycloheximide in $0.1 \mathrm{M}$ sodium phosphate buffer (pH 7.0)]. After 8 hours of shaking, the mycelia were collected by filtration, washed, and transferred to one liter of sterile distilled water. Mycelial clumps were allowed to settle for at most 3 minutes. If necessary, the filtration procedure was repeated so that fine and homogeneous mycelia could be collected and resuspended for use in the resting cell experiments. From this suspension, duplicate 8-ml samples were removed for dry weight determinations. Eightmilliliter samples (20 40 mg dry cell weight) were added to $2 \mathrm{ml}$ of 5 -fold concentrated resting cell medium in $50 \mathrm{ml}$ Erlenmeyer flasks. The final resting cell medium contained (per liter): $40 \mathrm{~g}$ lactose (sterilized separately); $2 \mathrm{~g}\left(\mathrm{NH}_{4}\right)_{2}-$ $\mathrm{HPO}_{4} ; 1.6 \mathrm{~g}$ sodium phenylacetate; $38 \mathrm{mg}$ cycloheximide; $0.3 \mathrm{M}$ sodium phosphate buffer $(\mathrm{pH}$ 7.0); and $160 \mathrm{ml}$ mineral salts mixture. ${ }^{4)}$ The flasks were incubated on the shaker at $25^{\circ} \mathrm{C}$. Samples $(0.3 \mathrm{ml})$ were removed at various times with a sterile Pasteur pipette, the mycelia were removed by filtration, and the filtrate was stored at $-20^{\circ} \mathrm{C}$ for a maximum of 24 hours prior to penicillin determination. Penicillin was determined by the agar diffusion assay method, by the use of filter paper disks and Bacillus subtilis ATCC 6051 as the assay organism.

As shown in Fig. 1, mycelia prepared as above produced penicillin at a linear rate for about 10 hours. As one would expect, production was enhanced by the penicillin precursors, valine and cysteine, and was inhibited by lysine.

To determine whether lysine inhibition of homocitrate synthase was responsible for inhibition of penicillin synthesis, we added intermediates of the lysine biosynthetic pathway. As expected, $\alpha$-aminoadipate reversed lysine inhibition (Fig. 2). More important was the observation that $\alpha$-ketoadipate and homocitrate also reversed lysine inhibition of penicillin biosynthesis. The reversal by homocitrate proves that homocitrate synthase is the crucial site for lysine inhibition of penicillin biosynthesis.

\section{Summary}

Homocitrate reverses the lysine inhibition of 
Fig. 1. Effect of amino acids on penicillin formation by starved, washed mycelia of Penicillium chrysogenum Wis. 54-1255 in a resting cell medium

The medium contained lactose, sodium phenylacetate, ammonium phosphate, mineral salts, sodium phosphate buffer, and cycloheximide (as described in the text).

L-Valine and L-cysteine were used at $200 \mu \mathrm{g} / \mathrm{ml}$ and L-lysine at $400 \mu \mathrm{g} / \mathrm{ml}$.

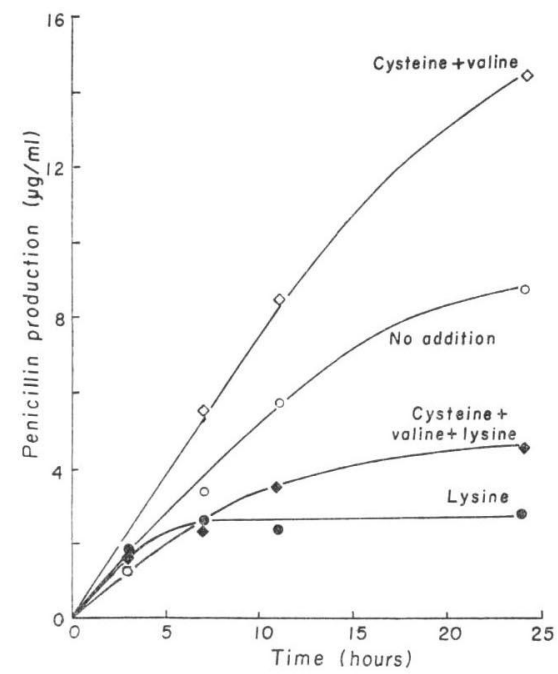

penicillin biosynthesis. Since lysine is known to inhibit homocitrate synthase, reversal by the reaction product identifies this enzyme as the crucial site of the lysine effect.

\section{Acknowledgements}

We thank J. K. Bhattacharjee and H. Broquist for homocitric acid. C. F. was supported partially by the Deutsche Forschungsgemeinschaft. The work was supported by National Science Foundation Grant No. BMS75-17527.

\section{References}

1) Demain, A. L.: Inhibition of penicillin formation by lysine. Arch. Biochem. Biophys. 67: $244 \sim 245,1957$
Fig. 2. Reversal of lysine inhibition of penicillin formation by homocitrate, $\alpha$-ketoadipate, and $\alpha$ aminoadipate

Starved, washed mycelia of Penicillium chrysogenum Wis. 54-1255 were incubated in a resting cell medium containing lactose, sodium phenylacetate, ammonium phosphate, mineral salts, sodium phosphate buffer, and cycloheximide (as described in the text) plus L-valine and L-cysteine at $200 \mu \mathrm{g} / \mathrm{ml}$ each. The concentration of the additives were $10 \mathrm{~mm}$ except for L-lysine, which was used at 4.5 mM.

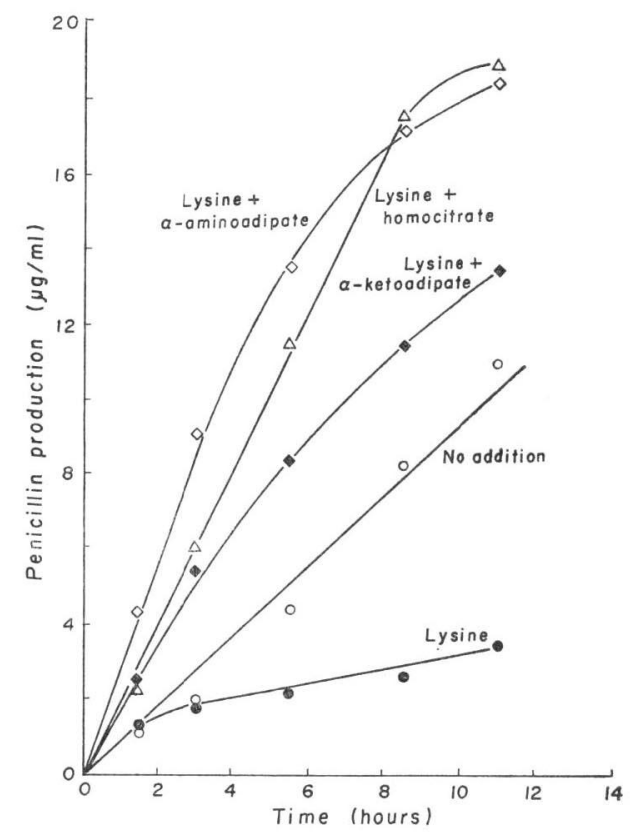

2) Somerson, N. L.; A. L. Demain \& T. D. NUNHEIMER: Reversal of lysine inhibition of penicillin production by $\alpha$-aminoadipic acid or adipic acid. Arch. Biochem. Biophys. 93: 238 241, 1961

3) Masurekar, P. S. \& A. L. Demain: Lysine control of penicillin biosynthesis. Canad. J. Microbiol. 18: 1045 1048, 1972

4) Demain, A. L. \& P. S. Masurekar: Lysine inhibition of in vivo homocitrate synthesis in Penicillium chrysogenum. J. Gen. Microbiol. 82: $143 \sim 151,1974$ 